\title{
Moderate Immune Presence
}

National Cancer Institute

\section{Source}

National Cancer Institute. Moderate Immune Presence. NCI Thesaurus. Code C159474.

Greater than 20-50 percent of the tissue surface area is occupied by immune cell infiltration. 